\title{
Effects of octreotide on sleep apnoea and tongue volume (magnetic resonance imaging) in patients with acromegaly
}

\author{
B L Herrmann, T E Wessendorf ${ }^{1}$, W Ajaj ${ }^{2}$, S Kahlke, H Teschler ${ }^{1}$ and K Mann \\ Division of Endocrinology, Department of Internal Medicine, University of Essen, Hufelandstrasse 55, D-45 122 Essen, Germany, ${ }^{1}$ Department \\ of Respiratory and Sleep Medicine, Ruhrlandklinik, University of Essen, Essen, Germany and ${ }^{2}$ Department of Radiology, University of Essen, \\ Essen, Germany \\ (Correspondence should be addressed to B L Herrmann; Email: burkhard.herrmann@uni-essen.de)
}

\begin{abstract}
Objectives: Sleep apnoea has been consistently reported to occur in acromegaly. Both obstructive apnoeas, in which apnoeas are due to intermittent obstruction of the upper airways, as well as central apnoeas are known to occur. Because the relationship between disease activity and severity of sleep apnoea is currently unclear, we have performed a prospective study to address this issue.

Design and methods: In 14 newly diagnosed patients with active acromegaly (eight females and six males; mean age 57 44 years; IGF-I $583 \pm 48 \mu \mathrm{g} / \mathrm{l}$; GH $13.5 \pm 7.0 \mu \mathrm{g} / \mathrm{l}$ (means \pm S.E.M.)), tongue volume and signal intensity of the tongue were examined by magnetic resonance imaging and sleep apnoea was characterised by polysomnography before and after 6 months of treatment with octreotide acetate (Sandostatin LAR 10-30 mg every 4 weeks i.m.).

Results: The initial tongue volume was significantly higher in patients with acromegaly $(151 \pm 9 \mathrm{ml}$; females $133 \pm 10 \mathrm{ml}$; males $172 \pm 10 \mathrm{ml}$ ) in comparison with the body mass index (BMI)- and agematched healthy control group $(97 \pm 5 \mathrm{ml}, \quad P<0.001$; females $75 \pm 1 \mathrm{ml}, \quad P<0.001$; males $120 \pm 3 \mathrm{ml}, P<0.003)$. After treatment with octreotide, IGF-I was normalised within the ageadjusted normal range in $50 \%$ of the patients. In these patients, tongue volume significantly decreased $(120 \pm 14 \mathrm{ml}, P<0.05)$ in comparison with the persistent uncontrolled group of acromegalics $(137 \pm 10 \mathrm{ml}, P=$ not significant). Overall, tongue volume $(128 \pm 8 \mathrm{ml}, P<0.05)$ and the signal intensity ratio of the tongue decreased significantly after treatment with octreotide acetate (120 $3 \mathrm{vs}$ $105 \pm 3, P=0.003)$. The BMI-adjusted tongue volume correlated with IGF-I levels $(r=0.60$, $P<0.002)$ and the disease duration $(r=0.71, P=0.006)$. At baseline, 50\% had obstructive sleep apnoea with a mean respiratory disturbance index (RDI) of $>20 / \mathrm{h}$ (range 5.1-91.5) and no patient had central sleep apnoea. After 6 months of octreotide treatment, there was a $28 \pm 10 \%$ decrease in RDI. However, RDI did not correlate with IGF-I or GH levels, but correlated positively with BMI $(r=0.58, P=0.001)$ and age $(r=0.46, P=0.02)$.

Conclusions: Obstructive sleep apnoea but not central sleep apnoea frequently occurs in patients with active acromegaly. Successful treatment with octreotide can decrease tongue volume, which may have benefits for coexisting sleep-disordered breathing.
\end{abstract}

European Journal of Endocrinology 151 309-315

\section{Introduction}

Patients with acromegaly predominantly have an increased risk of cardiovascular diseases (1-5), cancer $(6,7)$ and thyroid diseases (8, 9). Sleep apnoea, the phenomenon of recurrent cessation of airflow during sleep, has been consistently reported to occur in acromegaly (10-12). The mechanisms by which apnoeas occur in acromegaly have not been clearly delineated. Obstructive sleep apnoea has been attributed to soft-tissue hypertrophy of the upper airway which may predispose to obstruction during sleep either directly by tissue bulk or alteration of pharyngeal collapsibility $(13,14)$. Central sleep apnoea has been attributed to both partial obstruction leading to destabilisation of ventilatory control and to a defect of ventilatory control due to hormonal influence (15). The relationship between disease activity of acromegaly and sleep apnoea has been controversial, with some authors showing a positive correlation between levels of growth hormone $(\mathrm{GH})$ and sleep apnoea indices $(13,16)$ while others did not $(10,17)$.

The somatostatin analogue octreotide has been shown to reduce GH secretion by pituitary adenomas, and lead to an amelioration of the clinical features of acromegaly such as reduction of soft-tissue swelling $(18,19)$. Images from magnetic resonance imaging (MRI) are able to calculate the tongue volume and to 
determine the effect of treatment with octreotide in patients with acromegaly. To address this issue, we have performed a prospective study to characterise the sleep apnoea of patients with acromegaly and the effect of 6 months of treatment with octreotide acetate.

\section{Patients and methods}

\section{Patients}

Fourteen patients (eight females and six males) with a

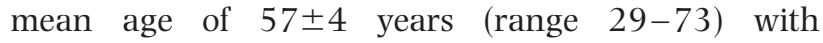
untreated active acromegaly were included in the study. They were recruited from the Clinic of Endocrinology, University of Essen in Germany over a 12-month period between 2002 and 2003. The diagnosis of acromegaly was made on the basis of physical examination, insulin-like growth factor-I (IGF-I) and GH levels after an oral glucose load (75 g) (20). Eight patients had microadenomas and six patients had macroadenomas. None of them had defects in visual field assessments. Four patients had thyrotrophin deficiency, one patient corticotrophin deficiency and one patient was luteinizing hormone/follicle-stimulating hormone deficient. Octreotide acetate (Sandostatin LAR; Novartis Pharma $\mathrm{GmbH}$, Basel, Switzerland) was started at a dose for $20 \mathrm{mg}$ every 4 weeks. After the third injection, the dose was reduced to $10 \mathrm{mg}$ every 4 weeks in those subjects with a mean 2-h GH profile (assessed by sampling every $30 \mathrm{~min})<1 \mu \mathrm{g} / \mathrm{l}$ and IGF-I levels within the normal range for age. In those with a mean 2 -h GH profile $>2.5 \mu \mathrm{g} / \mathrm{l}$ or IGF-I levels above the normal range for age, the dose was increased to $30 \mathrm{mg}$. Mean 2-h GH levels and IGF-I (mean of two fasting samples taken at a 1 -h interval) were assessed at baseline and weeks 12 and 24. Sleep studies (polysomnography) and tongue volume (MRI) were performed at baseline and after 6 months of treatment. The mean body mass index (BMI) was $30.8 \pm 1.5 \mathrm{~kg} / \mathrm{m}^{2}$ (range 26.1-43.4). Ten patients had arterial hypertension and were treated sufficiently with antihypertensive drugs. At baseline, the mean blood pressure was $129 \pm 4 / 74 \pm 2 \mathrm{mmHg}$.

\section{Control group}

A group of 50 volunteers, comparable for age $(51 \pm 2$ years, range $28-79)$, BMI $\left(25.2 \pm 1.2 \mathrm{~kg} / \mathrm{m}^{2}\right)$ and sex distribution ( 25 females and 25 males) served as nonacromegalic controls for the tongue volume (MRI). None of them had symptoms or signs of sleep apnoea syndrome.

\section{Hormone assays}

Serum GH levels were determined by a chemiluminescence immunometric assay (Nichols Institute Diagnostics GmbH, Bad Nauheim, Germany). The assay was calibrated against the WHO 1st International Standard $(80 / 505)$ for human $\mathrm{GH}$. The normal range was $\leq 5 \mu \mathrm{g} / \mathrm{l}$. Intra- and interassay coefficients of variation (CV) for a low point of the standard curve were $5.4 \%$ and $7.9 \%$ respectively. Plasma IGF-I concentrations were measured by an immunoradiometric assay (Nichols Institute Diagnostics $\mathrm{GmbH}$ ). The assay was calibrated against the WHO 1st International Reference reagent $87 / 518$. Intra- and interassay CV values for low IGF-I concentrations were $2.4 \%$ and $5.2 \%$ respectively. The normal range of IGF-I levels is $182-780 \mu \mathrm{g} / \mathrm{l}$ (16-24 years), $114-492 \mu \mathrm{g} / \mathrm{l} \quad(25-39$ years $)$, $90-360 \mu \mathrm{g} / \mathrm{l}(40-54$ years $)$ and $71-290 \mu \mathrm{g} / \mathrm{l}(>54$ years).

\section{Measurement of tongue volume}

All examinations were performed in the supine position on a 1.5 T MR scanner (Magnetom Sonata; Siemens Medical Systems, Erlangen, Germany) equipped with a high-performance gradient system characterised by an amplitude of $40 \mathrm{mT} / \mathrm{m}$ and a slew rate of $200 \mathrm{mT} / \mathrm{m}$ per ms. A head/neck phased-array surface coil was used for signal reception. Tongue volumes were measured by employing a two-dimensional (2D) Truefast imaging with steady-state procession (Fisp) sequence in the sagittal slice orientation without a distance factor (Fig. 1). A head phased-array surface coil was used for signal reception. In order to avoid motion artefacts the volunteers were asked not to move their tongue during the examination. Furthermore, all patients also underwent a 3D fast low-angle shot (FLASH) MR examination to evaluate the pharyngeal space and underwent a chewing and swallowing examination using a real-time True-Fisp with an oral contrast bolus. Similar examinations have been performed in previous studies (21-23). A head and neck phased-array surface coil was used for signal reception. For oral contrast administration, $0.5 \mathrm{ml}$ gadopentetate dimeglumine (Magnevist; Schering, Berlin, Germany) was mixed with $100 \mathrm{ml}$ of a normal commercially available vanilla pudding (concentration 1:200). After that a small piece of banana was mixed into this solution in order to increase the volume and viscosity of the contrast solution. Prior to the examination, all patients were asked to testchew and swallow a small bolus in the supine position outside of the magnet. There were no signs of aspiration in any of the patients with acromegaly. For the examinations, a plastic spoon was used to administer the contrast agent bolus while the subjects were in the supine position and placed in the head coil.

All images were transferred onto a workstation (Virtuosos; Siemens Medical Systems, Erlangen, Germany) and reviewed by a board certified radiologist. For quantitative analysis, regions of interest (ROI) were placed in the lumen of the tongue. Image noise, defined as the standard deviation of signal intensities measured in an ROI placed outside the body was 
a)
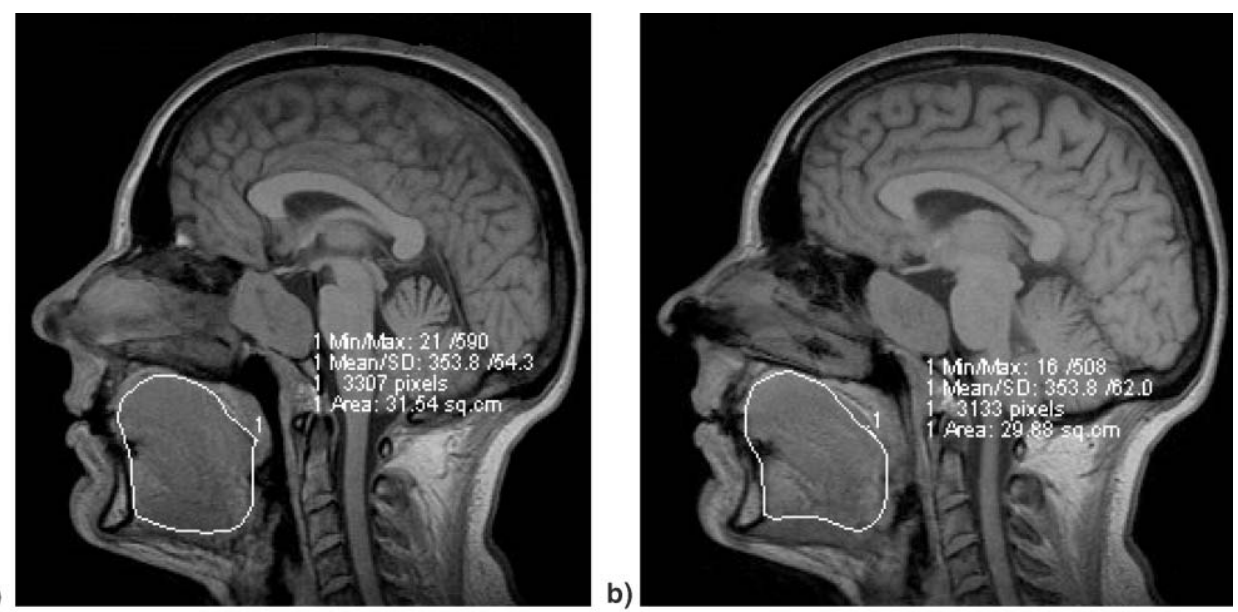

Figure 1 Measurement of the tongue volume by employing a 2D True-Fisp sequence in the sagittal slice orientation with MRI in one patient with acromegaly (a) at baseline and (b) after a 6-month treatment period with octreotide.

determined. Based on these measurements signal-tonoise ratios $(\mathrm{SNR})$ for representative parts were calculated: $\mathrm{SNR}=($ signal intensity $(\mathrm{SI})$ (tongue)/SI (standard deviation) noise).

\section{Polysomnography}

Complete overnight polysomnography (PSG) using the Compumedics System (Melbourne, Australia) was performed between 1000 and $1900 \mathrm{~h}$. Two-channel electroencephalography, electro-oculography and chin electromyography were performed using standard methods. Oronasal airflow was recorded by thermistor, and thoracic and abdominal respiratory efforts were measured by impedance plethysmography. Oxygen saturation was measured by finger pulse oximetry (ResMed Model 305A, ResMed, San Diego, CA, USA), and electrocardiography was performed from a precordial lead. Body position was monitored by a position sensor. During PSG, patients were observed by infrared video surveillance. Patients had been instructed to behave during the night as 'normally' as possible. Sleep data were staged manually according to standard criteria (24), and the arousals were scored according to the criteria of the American Sleep Disorders Association (25).

Apnoea was defined as cessation of airflow or reduction in thermistor signal to less than $10 \%$ of the normal flow and lasting for at least $10 \mathrm{~s}$. Apnoeas shorter than $10 \mathrm{~s}$ were counted if they were followed by either an arousal or an oxygen desaturation of $4 \%$ or more. Events were classified as obstructive (clear obstructive or mixed with a clear obstructive component in the event) or central events according to the respiratory effort channels. Hyponea was defined as a discernible reduction in airflow of at least $10 \mathrm{~s}$ duration followed either by arousal or a desaturation of $4 \%$ or more. The respiratory disturbance index (RDI) was calculated as the number of all respiratory events per hour of sleep. An RDI $<5$ was defined as normal, an RDI of 5-20 as borderline and an RDI of $>20$ as definitely pathological. Clear oxygen saturation $\left(\mathrm{SaO}_{2}\right)$ artifacts were excluded manually. Oxygen indices were then calculated by the software from the $\mathrm{SaO}_{2}$ curve with minimal $\mathrm{SaO}_{2}$ being the lowest saturation reached during sleep and with average minimal $\mathrm{SaO}_{2}$ being the mean of all saturation values reached during all respiratory events.

\section{Statistical analyses}

The data, if not marked otherwise, represent the mean \pm s.E. Differences between two groups were tested by Mann-Whitney U test as a non-parametric procedure. Absolute differences between time points (e.g. tongue volume at baseline and after the observation period) were analysed per group using the paired Wilcoxon signed rank test. All tests were twotailed; $P$ values $<0.05$ were considered statistically significant.

\section{Results}

\section{Effects of treatment on tongue volume}

The initial tongue volume was significantly higher $(36 \%)$ in patients with acromegaly $(151 \pm 9 \mathrm{ml})$ in comparison with the BMI- and age-matched healthy control group $(97 \pm 5 \mathrm{ml}, P<0.001)$. Females had a lower tongue volume than males. Females with active acromegaly $(133 \pm 10 \mathrm{ml})$ had a significantly higher tongue volume than the females in the control group $(75 \pm 1 \mathrm{ml}, P<0.001)$. Males with active acromegaly $(172 \pm 10 \mathrm{ml})$ had a significantly higher tongue volume than the males in the control group

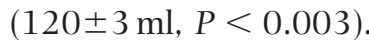

Seven patients received $20 \mathrm{mg}$, six patients $30 \mathrm{mg}$ and one patient $10 \mathrm{mg}$ octreotide acetate (Sandostatin LAR) every 28 days i.m. Overall, IGF-I levels significantly decreased from $583 \pm 40$ to $363 \pm 57 \mu \mathrm{g} / \mathrm{l}$ 
$(P<0.001)$ and $\mathrm{GH}$ decreased from $13.4 \pm 7.0 \mu \mathrm{g} / \mathrm{l}$ (range $2.1-103.0$ ) to $4.6 \pm 3.9 \mu \mathrm{g} / \mathrm{l}$ (range 0.6-40.5) $(P<0.001)$. After treatment with octreotide acetate, the age-adjusted IGF-I levels were normalised in 50\% of patients. In these patients, tongue volume significantly decreased $(120 \pm 14 \mathrm{ml}, P<0.05$ (Fig. 2)) in comparison with the persistent uncontrolled group of acromegalics $(137 \pm 10 \mathrm{ml}, P=$ not significant). Overall, tongue volume decreased significantly after treatment with octreotide acetate $(128 \pm 8 \mathrm{ml}, P<0.05)$. We have adjusted the tongue volume to the BMI because height and weight are positively related to the tongue volume. The IGF-I levels at baseline and after treatment correlated significantly with BMIadjusted tongue volume $(r=0.60, \quad P=0.002$ (Fig. 3)), whereas GH levels did not. Moreover, the disease duration correlated with the BMI-adjusted tongue volume $(r=0.71, P=0.006$ (Fig. 3$)$ ).

The signal intensity correlated positively with water/oedema and offers an exact quantitative analysis of the treatment effect on soft-tissue swelling. After treatment with octreotide, the signal intensity ratio of the tongue significantly decreased $(120 \pm 3$ vs $105 \pm 3$, $P=0.003)$. The signal intensity ratio of the tongue correlated significantly with IGF-I levels $(r=0.46$, $P=0.02$ (Fig. 3)).

\section{Effects of treatment on sleep-disordered breathing}

At baseline, $50 \%$ of patients had obstructive sleep apnoea with a mean RDI of $>20 /$ h (range 5.1-91.5) and no patient had central sleep apnoea. After 6 months of octreotide treatment, there was a $28 \pm 10 \%$ decrease in RDI. At baseline, $50 \%$ had an RDI $>20 / \mathrm{h}, 29 \%$ an RDI $11-20 / \mathrm{h}, 21 \%$ an RDI $5-10 / \mathrm{h}$ and none an RDI $<5 / \mathrm{h}$. After treatment, $46 \%$ had an RDI $>20 / \mathrm{h}, 8 \%$ an RDI $11-20 / \mathrm{h}, 38 \%$ an RDI

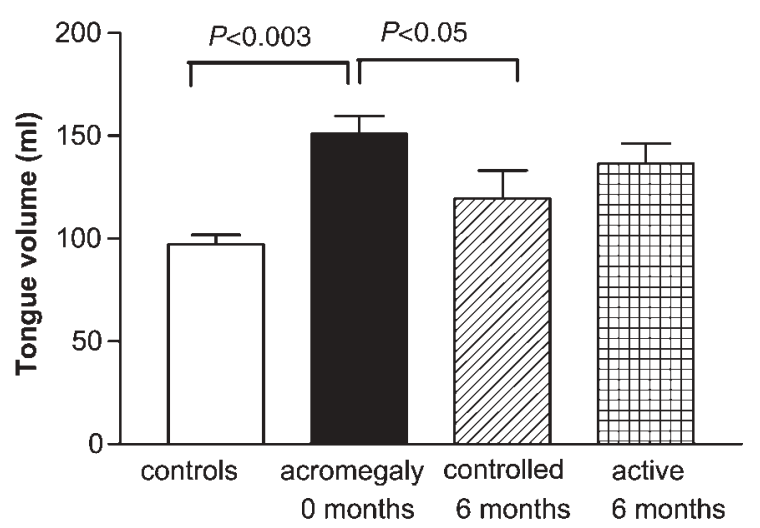

Figure 2 Tongue volume of controls (open bar), of patients with acromegaly at baseline (solid bar) and after a 6-month treatment period of octreotide with normal age-adjusted IGF-I levels $(n=7)$ (hatched bar) and persistent elevated IGF-I levels $(n=7)$ (crossed bar). (a)

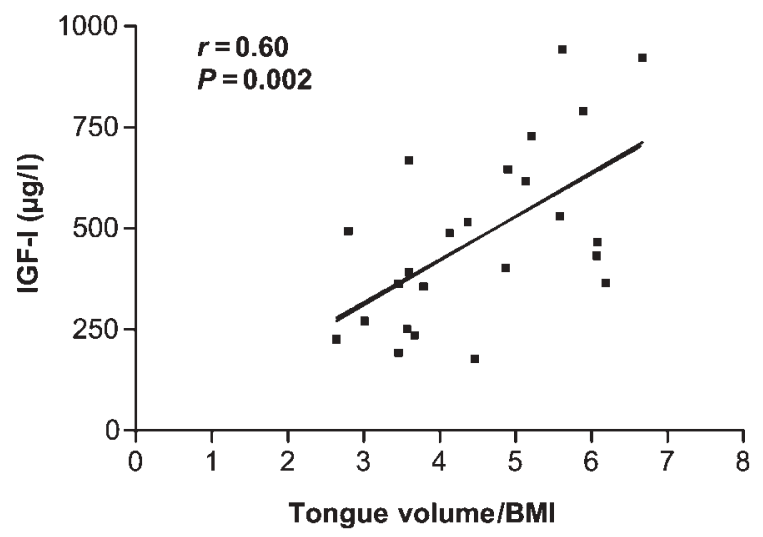

(b)

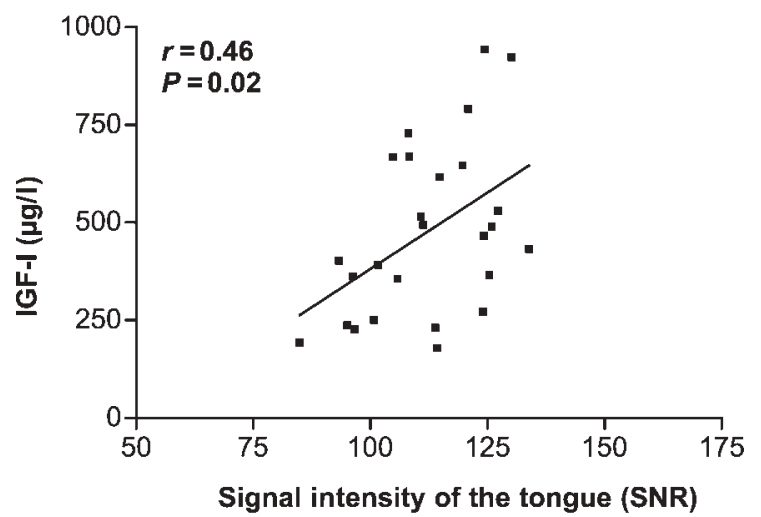

(c)

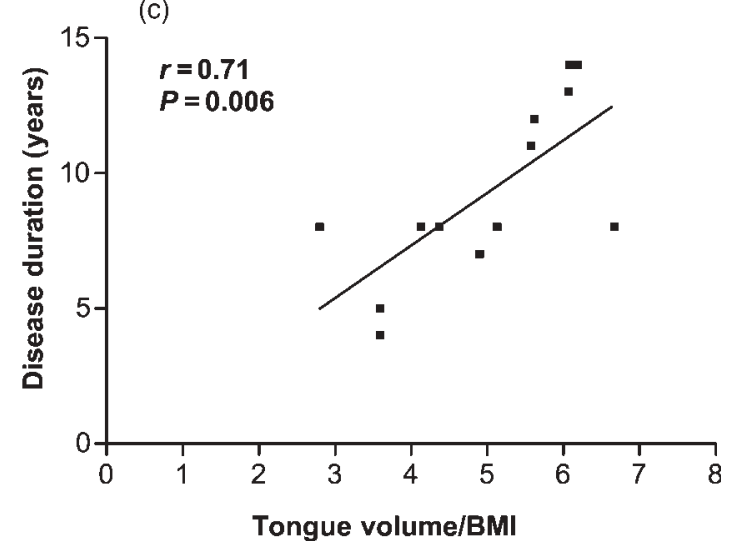

Figure 3 Correlation between IGF-I levels and BMI-adjusted tongue volume (a), signal intensities of the tongue (b) and correlation between disease duration and BMI-adjusted tongue volume (c) in 14 patients with newly diagnosed acromegaly before and after treatment with octreotide acetate over a 6-month period.

$5-10 / \mathrm{h}$ and $8 \%$ an RDI $<5 /$ h (Table 1 ). RDI decreased in $64 \%(9 / 14)$ of the patients (Fig. 4).

Although a decrease in mean levels of IGF-I and GH and an improvement in mean RDI were seen in the study group, no correlation was noted between the absolute decrease of IGF-I or GH levels and the changes 
Table 1 Distribution of RDI in 14 patients with newly diagnosed acromegaly before and after treatment with octreotide acetate over a 6-month period.

\begin{tabular}{lcc}
\hline & RDI baseline & RDI after 6 months \\
\hline$>20 / \mathrm{h}$ & $50 \%$ & $46 \%$ \\
$11-20 / \mathrm{h}$ & $29 \%$ & $8 \%$ \\
$5-10 / \mathrm{h}$ & $21 \%$ & $38 \%$ \\
$<5 / \mathrm{h}$ & $0 \%$ & $8 \%$ \\
\hline
\end{tabular}

in RDI. However, RDI correlated positively with the BMI $(r=0.58, P=0.001)$ and age $(r=0.46, P=0.02)$. Minimum oxygen saturation did not change significantly ( $81 \pm 3 \%$ at baseline vs $83 \pm 2 \%$ after 6 months).

\section{Discussion}

In the present study, we have demonstrated that MRI can sufficiently determine tongue size and that treatment with octreotide can effectively reduce tongue volume in patients with newly diagnosed acromegaly. Fifty percent had obstructive sleep apnoea with a mean RDI of $>20 / \mathrm{h}$. After treatment, we observed a $28 \%$ decrease of the number of apneic events.

RDI $>20 / h$

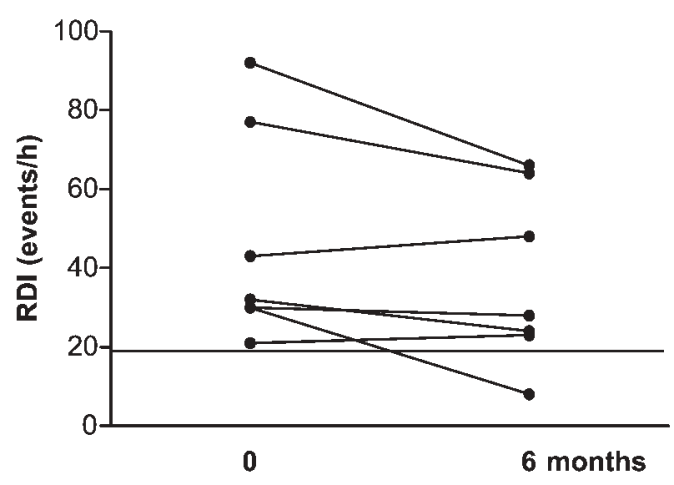

RDI $<20 / h$

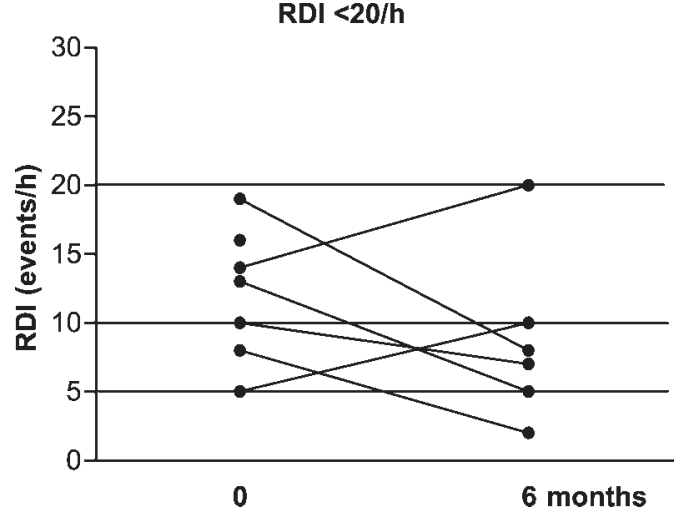

Figure 4 Changes in RDI in 14 patients with newly diagnosed acromegaly before and after treatment with octreotide acetate over a 6-month period.
Beside cardiovascular diseases and cancer, sleep apnoea is a further complication of $\mathrm{GH}$ excess in untreated acromegaly $(10,15-17)$. Considering the association of sleep-disordered breathing with cardioand cerebrovascular disease $(23,24)$, it becomes obvious that the increased mortality of patients with acromegaly may not only be due to cardiovascular diseases and cancer but also due to sleep apnoea. Moreover, it is now well established, that hypertension and cardiovascular diseases are associated with sleep apnoea. The prevalence of hypertension in obstructive sleep apnoea is up to three times higher than in the normal population $(25,26)$ Treatment of obstructive sleep apnoea with nasal continuous airway pressure therapy may result in a significant decrease in elevated blood pressure in hypertensive patients (27).

Sleep-disordered breathing can be classified as obstructive or central sleep apnoea. Grunstein et al. (10) reported that patients with a central form of sleep apnoea have significantly higher GH and IGF-I levels than patients with obstructive disease. Although Grunstein et al. speculated that increased brain somatostatin (a potential consequence of high circulating $\mathrm{GH}$ ) might be responsible for the generation of central apneic episodes, the success of octreotide in relieving central sleep apnoea argues against the proposed primary role of somatostatin as a causative agent (15). None of our patients with active acromegaly had predominantly central sleep apnea either before or after treatment, indicating that a larger number of acromegalic patients need to be studied to clarify this issue.

Consistent with previous studies, we observed that $50 \%$ of our patients with active acromegaly had moderate to severe obstructive sleep apnoea $(10,15)$. The soft-tissue swelling of the tongue might be responsible for the upper airway obstruction (26-28). Previous studies tried to characterise anatomical differences in acromegalic patients in comparison with healthy nonacromegalics by using lateral X-ray films with cephalometric landmarks and reference lines. From those studies $(27,29-31)$, there are anatomical skeletal abnormalities predisposing to obstructive sleep apnoea: maxillary and mandibular retrognathism, dorsocaudal rotation of the mandible, enlargement of the anterior and posterior facial height, and narrowing of the depth of the bony framework of the nasopharynx. Moreover, patients with acromegaly have a larger uvula and a narrowed pharyngeal airway space caused by changes in pharyngeal soft-tissue swelling than the healthy population $(27,29-31)$.

Besides a large uvula, macroglossia narrows pharyngeal airway space. MRI, compared with radiographs, has the advantage of more precise delineation of soft tissue and determination of tongue volume. The present study has shown that MRI of the pharynx revealed a significantly higher (plus 36\%) tongue volume in patients with active acromegaly in comparison with an age-matched healthy control group. We have 
adjusted the tongue volume to the BMI, because height and weight are positively related to the tongue volume. IGF-I levels correlated closely with the BMI-adjusted tongue volume. The evidence that only a decrease in IGF-I could be beneficial on organ hypertrophy has already been shown by analysis of cardiac size in a similar cohort treated for the same time (32). As has been shown in several studies about complications in patients with acromegaly $(1,33)$, the disease duration correlated with the BMI-adjusted tongue volume.

Octreotide acetate, a long-acting somatostatin analogue which effectively reduces GH secretion in acromegaly, has been shown to decrease soft-tissue swelling in acromegaly $(18,19)$. After treatment with octreotide acetate, tongue volume significantly decreased, despite the IGF-I normalisation in only $50 \%$ of the patients after 6 months.

Although we have seen overall a $28 \%$ decrease of RDI after treatment with octreotide, RDI did not normalize in patients with severe obstructive sleep apnoea (RDI $>20 / \mathrm{h}$ ). The mechanisms leading to improvement have not been elucidated, since sleep apnoea may persist despite normalisation of $\mathrm{GH}$ levels or may improve markedly with only partial biochemical remission $(17,34)$. Similar to our observations, Grunstein et al. (17) did not find any association between hormonal activity and the presence of sleep apnoea, in contrast to a previous study by Hart and collegues (16) who reported that only patients with active acromegaly had sleep apnoea. Despite the lack of definitive documentation, it is generally accepted that improvement of sleep apnoea is mediated through a decrease in upper airway obstruction secondary to several factors, including reduction of upper airway soft-tissue bulk or collapsibility and improvement of upper airway muscle function. Moreover, RDI correlated positively with the BMI and age, indicating that independent factors of the disease activity may influence sleep disorders in patients with acromegaly. Considering the fact that body fat is increased in patients with acromegaly after cure or successful treatment $(35,36)$, long-term observations of sleep apnoea in acromegaly is recommended.

Although we were able to demonstrate a correlation between the improvement in biochemical activity via IGF-I and soft-tissue swelling of the tongue, we did not find any correlation between apneic episodes and tongue volume or disease activity. This may be due to the small number of patients and the multifactorial pathogenesis of the sleep apnoea syndrome.

In summary, our findings have shown that MRI revealed a higher tongue size in patients with acromegaly and that treatment with octreotide significantly reduces tongue volume. The presence of $50 \%$ of severe obstructive sleep apnoea in patients with active acromegaly indicates that screening for sleep apnoea should be included in the diagnostic work-up of acromegalic patients.

\section{Acknowledgements}

This work was supported by grants from Novartis Pharma GmbH, Nürnberg, Germany.

\section{References}

1 Colao A, Cuocolo A, Marzullo P, Nicolai E, Ferone D, Della Morte AM, Petretta M, Salvatore M \& Lombardi G. Impact of patient's age and disease duration on cardiac performance in acromegaly: a radionuclide angiography study. Journal of Clinical Endocrinology and Metabolism 199984 1518-1523.

2 Colao A, Cuocolo A, Marzullo P, Nicolai E, Ferone D, Della Morte AM, Pivonello R, Salvatore M \& Lombardi G. Is the acromegalic cardiomyopathy reversible? Effect of 5-year normalization of growth hormone and insulin-like growth factor I levels on cardiac performance. Journal of Clinical Endocrinology and Metabolism 200186 1551-1557.

3 Herrmann BL, Bruch C, Saller B, Ferdin S, Dagres N, Ose C, Erbel R \& Mann K. Occurrence of ventricular late potentials in patients with active acromegaly. Clinical Endocrinology $2001 \quad 55$ 201-207.

4 Herrmann BL, Bruch C, Saller B, Bartel T, Ferdin S, Erbel R \& Mann K. Acromegaly: evidence for a direct relation between disease activity and cardiac dysfunction in patients without ventricular hypertrophy. Clinical Endocrinology 200256 595-602.

5 Herrmann BL, Brandt-Mainz K, Saller B, Bruch C, Wieneke H, Kugler C, Ferdin S, Hahn S, Erbel R, Bockisch A \& Mann K. Myocardial perfusion abnormalities in patients with active acromegaly. Hormone and Metabolic Research 200335 183-188.

6 Orme SM, McNally RJ, Cartwright RA \& Belchetz PE. Mortality and cancer incidence in acromegaly: a retrospective cohort study. United Kingdom Acromegaly Study Group. Journal of Clinical Endocrinology and Metabolism $1998 \mathbf{8 3} 2730-2734$.

7 Popovic V, Damjanovic S, Micic D, Nesovic M, Djurovic M, Petakov M, Obradovic S, Zoric S, Simic M, Penezic Z \& Marinkovic J. Increased incidence of neoplasia in patients with pituitary adenomas. The Pituitary Study Group. Clinical Endocrinology 1998 $49441-445$.

8 Gasperi M, Martino E, Manetti L, Arosio M, Porretti S, Faglia G, Mariotti S, Colao AM, Lombardi G, Baldelli R, Camanni F \& Liuzzi A. Prevalence of thyroid diseases in patients with acromegaly: results of an Italian multi-center study. Journal of Endocrinological Investigation $200225240-245$.

9 Herrmann BL, Baumann H, Janssen OE, Goerges R, Schmid KW \& Mann K. Impact of disease activity on thyroid diseases in patients with acromegaly: basal evaluation and follow-up. Experimental and Clinical Endocrinology and Diabetes $2004112225-284$.

10 Grunstein RR, Ho KY \& Sullivan CE. Sleep apnea in acromegaly. Annals of Internal Medicine 1991115 527-532.

11 Grunstein RR, Ho KY, Berthon-Jones M, Stewart D \& Sullivan CE. Central sleep apnea is associated with increased ventilatory response to carbon dioxide and hypersecretion of growth hormone in patients with acromegaly. American Journal of Respiratory and Critical Care Medicine 1994150 496-502.

12 Barkan A. Acromegalic arthropathy and sleep apnea. Journal of Endocrinology 1997155 (Suppl 1) S41-S45 discussion S45.

13 Rosenow F, Reuter S, Deuss U, Szelies B, Hilgers RD, Winkelmann W \& Heiss WD. Sleep apnoea in treated acromegaly: relative frequency and predisposing factors. Clinical Endocrinology 199645 563-569.

14 Isono S, Saeki N, Tanaka A \& Nishino T. Collapsibility of passive pharynx in patients with acromegaly. American Journal of Respiratory and Critical Care Medicine 1999160 64-68.

15 Grunstein RR, Ho KY, Berthon-Jones M, Stewart D \& Sullivan CE. Central sleep apnea is associated with increased ventilatory response to carbon dioxide and hypersecretion of growth hormone in patients with acromegaly. American Journal of Respiratory and Critical Care Medicine 1994150 496-502. 
16 Hart TB, Radow SK, Blackard WG, Tucker HS \& Cooper KR. Sleep apnea in active acromegaly. Archives of Internal Medicine 1985 $145865-866$

17 Grunstein RR, Ho KK \& Sullivan CE. Effect of octreotide, a somatostatin analog, on sleep apnea in patients with acromegaly. Annals of Internal Medicine 1994121 478-483.

18 Lamberts SW, van Koetsveld P \& Hofland L. A close correlation between the inhibitory effects of insulin-like growth factor-I and SMS 201-995 on growth hormone release by acromegalic pituitary tumours in vitro and in vivo. Clinical Endocrinology 198931 401-410.

19 Melmed S. Acromegaly. New England Journal of Medicine 1990 322 966-977.

20 Giustina A, Barkan A, Casanueva FF, Cavagnini F, Frohman L, Ho K, Veldhuis J, Wass J, Von Werder K \& Melmed S. Criteria for cure of acromegaly: a consensus statement. Journal of Clinical Endocrinology and Metabolism 200085 526-529.

21 Schwab RJ, Pasirstein M, Pierson R, Mackley A, Hachadoorian R, Arens R, Maislin G \& Pack AI. Identification of upper airway anatomic risk factors for obstructive sleep apnea with volumetric magnetic resonance imaging. American Journal of Respiratory and Critical Care Medicine $2003 \mathbf{1 6 8 5 2 2 - 5 3 0 .}$

22 Stuck BA, Kopke J, Maurer JT, Verse T, Kuciak G, Duber C \& Hormann K. Evaluating the upper airway with standardized magnetic resonance imaging. Laryngoscope $2002112552-558$.

23 Gao XM, Zeng XL, Fu MK \& Huang XZ. Magnetic resonance imaging of the upper airway in obstructive sleep apnea before and after oral appliance therapy. Chinese Journal of Dental Research $1999227-35$.

24 Hori T, Sugita Y, Koga E, Shirakawa S, Inoue K, Uchida S, Kuwahara H, Kousaka M, Kobayashi T, Tsuji Y, Terashima M, Fukuda K \& Fukuda N. Proposed supplements and amendments to 'A Manual of Standardized Terminology, Techniques and Scoring System for Sleep Stages of Human Subjects', the Rechtschaffen \& Kales (1968) standard. Psychiatry and Clinical Neurosciences 200155 305-310.

25 EEG arousals: scoring rules and examples: a preliminary report from the Sleep Disorders Atlas Task Force of the American Sleep Disorders Association. Sleep 199215 173-184.

26 Dostalova S, Smahel Z \& Sonka K. Craniofacial abnormalities in sleep apnoea syndrome. Acta Chiurgica Plastica 199840 49-53.

27 Dostalova S, Sonka K, Smahel Z, Weiss V, Marek J \& Horinek D. Craniofacial abnormalities and their relevance for sleep apnoea syndrome aetiopathogenesis in acromegaly. European Journal of Endocrinology $2001 \mathbf{1 4 4} 491-497$.

28 Ip MS, Tan KC, Peh WC \& Lam KS. Effect of Sandostatin LAR on sleep apnoea in acromegaly: correlation with computerized tomographic cephalometry and hormonal activity. Clinical Endocrinology $200155477-483$.

29 Bacon WH, Turlot JC, Krieger J \& Stierle JL. Cephalometric evaluation of pharyngeal obstructive factors in patients with sleep apneas syndrome. Angle Orthodontist 199060 115-122.

30 Hochban W, Ehlenz K, Conradt R \& Brandenburg U. Obstructive sleep apnoea in acromegaly: the role of craniofacial changes. European Respiratory Journal 199914 196-202.

31 Hochban W \& Brandenburg U. Morphology of the viscerocranium in obstructive sleep apnoea syndrome - cephalometric evaluation of 400 patients. Journal of Cranio-Maxillofacial Surgery 199422 205-213.

32 Colao A, Marzullo P, Ferone D, Spinelli L, Cuocolo A, Bonaduce D, Salvatore M, Boerlin V, Lancranjan I \& Lombardi G. Cardiovascular effects of depot long-acting somatostatin analog Sandostatin LAR in acromegaly. Journal of Clinical Endocrinology and Metabolism $2000853132-3140$.

33 Colao A, Ferone D, Marzullo P \& Lombardi G. Systemic complications of acromegaly: epidemiology, pathogenesis, and management. Endocrine Reviews $200425102-152$.

34 Pekkarinen T, Partinen M, Pelkonen R \& Iivanainen M. Sleep apnoea and daytime sleepiness in acromegaly: relationship to endocrinological factors. Clinical Endocrinology $1987 \quad 27$ 649-654.

35 Brummer RJ, Lonn L, Kvist H, Grangard U, Bengtsson BA \& Sjostrom L. Adipose tissue and muscle volume determination by computed tomography in acromegaly, before and 1 year after adenomectomy. European Journal of Clinical Investigation 199323 199-205.

36 Sonksen PH, Salomon F \& Cuneo R. Metabolic effects of hypopituitarism and acromegaly. Hormone Research 199136 (Suppl 1) $27-31$.

Received 29 March 2004

Accepted 24 May 2004 